OPEN ACCESS

Edited by:

Andras Lakatos,

University of Cambridge,

United Kingdom

Reviewed by:

Aviva Tolkovsky,

University of Cambridge,

United Kingdom

Claire S. Durrant,

University of Edinburgh,

United Kingdom

*Correspondence:

Louisa Nitsch

louisa.nitsch@ukb.uni-bonn.de

Specialty section

This article was submitted to

Dementia and Neurodegenerative

Diseases,

a section of the journa

Frontiers in Neurology

Received: 08 December 2020

Accepted: 15 March 2021

Published: 07 April 2021

Citation:

Nitsch L, Schneider L, Zimmermann J and Müller M (2021) Microglia-Derived Interleukin 23: A Crucial Cytokine in

Alzheimer's Disease?

Front. Neurol. 12:639353. doi: 10.3389/fneur.2021.639353

\section{Microglia-Derived Interleukin 23: A Crucial Cytokine in Alzheimer's Disease?}

\author{
Louisa Nitsch $^{1 *}$, Linda Schneider ${ }^{2}$, Julian Zimmermann ${ }^{1}$ and Marcus Müller ${ }^{1}$ \\ ${ }^{1}$ Department of Neurology, University Hospital Bonn, Bonn, Germany, ${ }^{2}$ Department of Surgery, University Hospital Bonn, \\ Bonn, Germany
}

Neuronal cell death, amyloid $\beta$ plaque formation and development of neurofibrillary tangles are among the characteristics of Alzheimer's disease (AD). In addition to neurodegeneration, inflammatory processes such as activation of microglia and astrocytes are crucial in the pathogenesis and progression of AD. Cytokines are essential immune mediators of the immune response in $A D$. Recent data suggest a role of interleukin 23 (IL-23) and its p40 subunit in the pathogenesis of $A D$ and corresponding animal models, in particular concerning microglia activation and amyloid $\beta$ plaque formation. Moreover, in animal models, the injection of anti-p40 antibodies resulted in reduced amyloid $\beta$ plaque formation and improved cognitive performance. Here, we discuss the pathomechanism of IL-23 mediated inflammation and its role in AD.

Keywords: interleukin 23, microglia, neuroinflammation, antibody therapy, Alzheimer's disease

\section{INTRODUCTION}

Alzheimer's disease (AD) is the most common form of dementia and affects millions of people worldwide (1). Despite the immense progress in AD research over the recent years, many aspects of the underlying pathomechanism remain elusive and new approaches for effective therapies are needed. Besides neurodegeneration, the disease-accelerating role of neuroinflammation has become a focus of research in AD. Since the central role of interleukin 23 (IL-23) in neuroinflammation, especially in multiple sclerosis (MS), has become clear, several interesting studies about AD and IL-23 have been published. Therefore, this review provides an overview of the current data on IL-23 mediated neuroinflammation in $\mathrm{AD}$, open aspects for further research and possible therapeutic approaches.

\section{IL-23}

Cytokines are peptide hormones that act as messengers of the immune system and modulate the immune response in an autocrine, paracrine, or endocrine manner (2). They regulate activation or inhibition of immune cells, control their differentiation, proliferation and chemotaxis. In particular, the successful application of antibodies modulating the cytokine function for the treatment of a variety of diseases has further advanced the research in the field of cytokines and cytokine-inhibiting therapies. 
A subgroup of cytokines are the interleukins. IL-23 consists of a unique 19 and a common p40 subunit, which is shared by the structurally related IL-12 (3). It appears that the heterodimeric molecule is the bioactive cytokine and both subunits, p19/p40 for IL-23 and p35/p40 for IL-12 must be co-expressed in the same cell to generate the bioactive form. However, some data also show an effector function of p40 alone as discussed below. Since the first study demonstrated that IL-23 and not the structurally similar IL-12 is the central cytokine contributing to the pathogenesis of autoimmune diseases $(4,5)$, the importance of IL-23 in neuroinflammation has been further deciphered in many preclinical and clinical studies. IL-23 is primarily secreted by antigen presenting cells (APC) like dendritic cells, macrophages, and $\mathrm{B}$ cells $(3,6,7)$. The local production of IL-23 in the CNS has been demonstrated for astrocytes and infiltrating macrophages under inflammatory conditions $(5,8)$. In addition, some studies demonstrated the secretion of the IL$12 / \mathrm{IL}-23$ subunit $\mathrm{p} 40$ by microglia $(9,10)$, while others provided evidence that microglia secrete the bioactive cytokine IL-23 upon activation (11-13).

Figure 1 summarizes how IL-23 activates the immune system. Best known responders to IL-23 stimulation are the CD4 T helper subset T helper 17 (Th17) cells, a distinct subpopulation of $\gamma \delta$ $\mathrm{T}$ cells, subsets of natural killer $\mathrm{T}$ cells, and innate lymphoid cells (14). IL-23 binds to its specific receptor complex, which consists of a unique IL-23 receptor subunit and a IL12 $\beta 1$ subunit. $\gamma \delta \mathrm{T}$ cells express the IL-23 receptor constitutively, but naive CD4+ cells lack the IL-23 receptor. CD4+ cells are therefore first activated by other cytokines such as the transforming growth factor (TGF $\beta$ ), IL-6 or IL-21, then differentiate into Th17 cells and express the IL-23 receptor (15-17).

By binding to the IL-23 receptor, IL-23 leads to a conformational change of the receptor, which promotes the phosphorylation of Janus kinase 2 (JAK2) and tyrosine kinase 2 (Tyk2) leading to phosphorylation of signal transducer and activator of transcription (STAT) factors with STAT3 primarily activated (18). The activated STAT protein enters the nucleus to exert its biological effects. This leads to the secretion of the Th17 cell characteristic cytokines IL-17A, IL-17F and several other proinflammatory cytokines like IL-22, the granulocytemacrophage colony-stimulating factor (GM-CSF) or the tumor necrosis factor (TNF $\alpha)$ (14).

Among the different cell subtypes expressing the IL-23 receptor, Th17 cells could be established as key players in neuroinflammation, particularly in MS (19, 20). Beside these well-known responders of lymphocytic origin, expression of the IL-23 receptor on macrophages/monocytes, microglia, and dendritic cells was described $(21,22)$, enabling these cells to

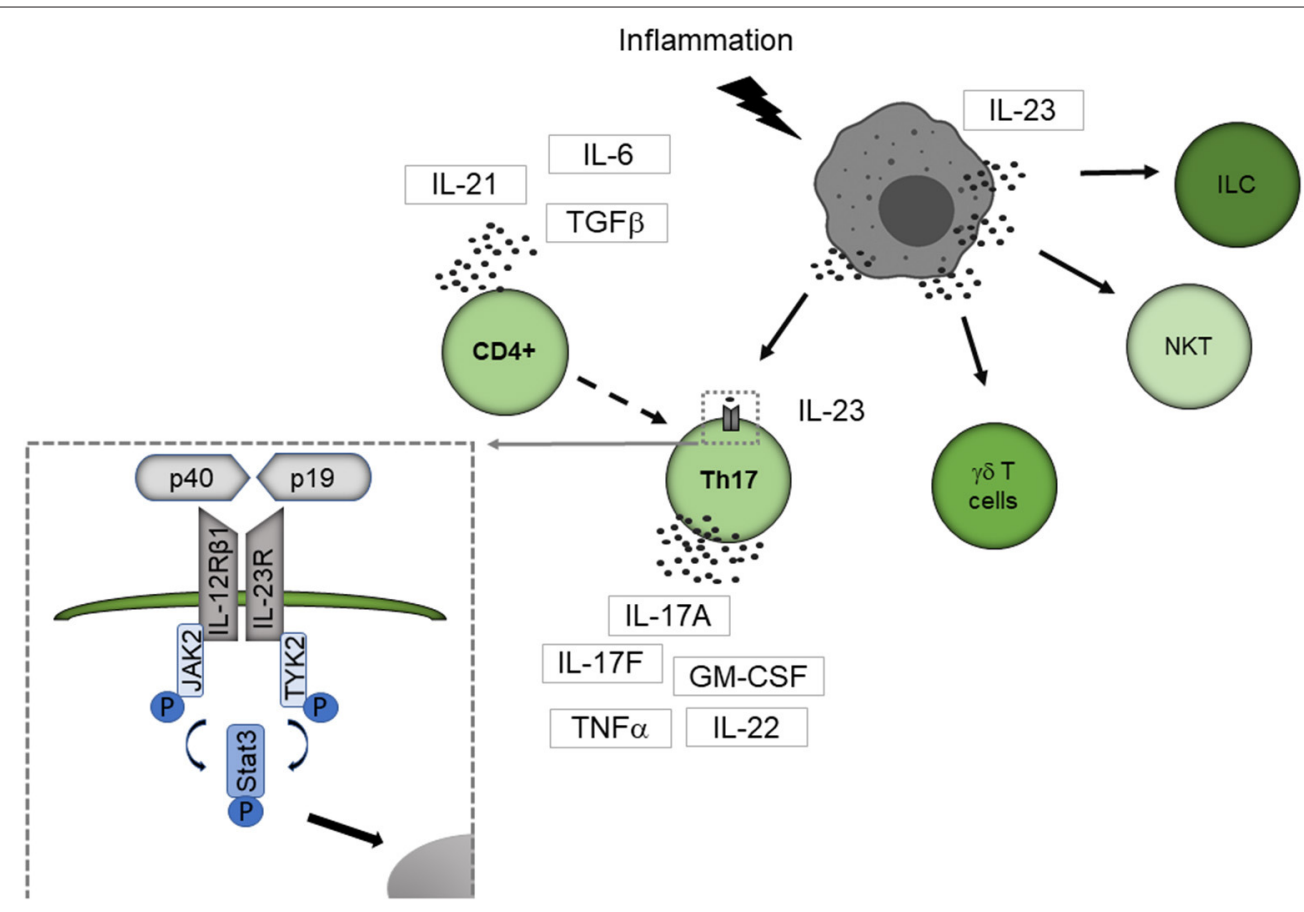

FIGURE 1 | IL-23 mediated activation of the immune system. IL-23 is primarily secreted by APC like dendritic cells, macrophages, and B cells. Best known responders to IL-23 stimulation are Th17 cells, a distinct subpopulation of $\gamma \delta$ T cells, subsets of natural killer T cells, and innate lymphoid cells. IL-23 binds to its specific receptor complex, which consists of a unique IL-23 receptor subunit and a IL12 $\beta 1$ subunit. $\gamma \delta$ T cells express the IL-23 receptor constitutively, but naive CD4+ cells lack the IL-23 receptor. CD4+ cells are therefore first activated by other cytokines such as TGF- $\beta$, IL-6, or IL-21, then differentiate into Th17 cells and express the IL-23 receptor. By binding to the IL-23 receptor, IL-23 leads conformational change of the receptor that promotes the phosphorylation of JAK2 and Tyk2 leading to phosphorylation of STAT factors. Thereby STAT3 is primarily activated. The activated STAT protein enters the nucleus to exert its biological effects. ILC, innate lymphoid cell; NKT, natural killer cell. 
directly interact with IL-23. Thereby, IL-23 enhances the cytokine production of IL-23 receptor expressing myeloid cells $(21,22)$.

\section{IL-23 AND NEUROINFLAMMATION}

The crucial role of IL-23 in the pathogenesis of a vast variety of autoimmune diseases like inflammatory bowel diseases, rheumatoid arthritis, and psoriasis has been clearly demonstrated [(23-27), summarized in Table 1]. IL-23 is also important in the atherogenesis and progression of atherosclerotic plaques $(28,29)$.

Numerous studies could demonstrate the significance of IL23 in neuroinflammation as well. Most of the data on IL-23 and neuroinflammation have been derived from studies on the pathogenesis of MS and corresponding animal models (38). The central role of IL-23 in the development of MS is beyond doubt. IL-23 is increased in serum, cerebrospinal fluid (CSF), and lesional tissue of MS patients (13-15). Animal models emphasize the non-redundant role of IL-23 in MS, as an experimental autoimmune encephalitis cannot be induced in mice lacking IL23 or the receptor complex (30-32). Nevertheless, there are also studies suggesting IL-23 is critical in stroke patients, especially in the postischemic inflammatory phase $(33,34)$. Furthermore, the IL-23 signaling pathway is part of the defense mechanism in viral, bacterial, and fungal infections of the CNS (35-37). To further investigate how IL-23 mediates neuroinflammation in different animal models, we have recently established a mouse model with astrocyte-specific expression of IL-23 revealing unexpectedly, a spontaneous B cell accumulation in the cerebellum (39).

With the increasing number of studies demonstrating the importance of IL-23 in neuroinflammation, several studies have also investigated the influence of IL-23 on AD. Therefore, this review will give an overview of the role of IL- 23 in AD.

\section{AD AND NEUROINFLAMMATION}

Characteristics of $\mathrm{AD}$ are amyloid $\beta$ ( $\mathrm{A} \beta$ ) plaques, which are extracellular deposits of $A \beta$ derived from the $\beta$-amyloid precursor protein (APP), neurofibrillary tangles composed of hyperphosphorylated tau and neuronal cell death (40). In addition to neurodegeneration, neuroinflammation is crucial in the pathogenesis and progression of $\mathrm{AD}$ (40). Although it is not clear to what extent neuroinflammation contributes to the pathogenesis of $\mathrm{AD}$, it is generally acknowledged that the immune system influences the disease progression.

Neuroinflammation in AD is mainly promoted by CNSresident cells like microglia and astrocytes. Microglia are CNSresident cells of myeloid origin with immune-modulating and phagocytic capabilities (41). Activation of the innate immune system in $A D$ seems to follow $A \beta$ deposition. However, studies of patients with mild cognitive impairment demonstrate neuroinflammation even in the early phase $(42,43)$.

$\mathrm{A} \beta$ plaques are surrounded by reactive astrocytes and activated microglial cells $(44,45)$. The role of microglia in $\mathrm{AD}$ initiation and progression are debated, with conflicting reports regarding their detrimental or protective function (46). Microglia and astrocytes can remove $A \beta$ by uptake and degradation
TABLE 1 | Role of IL-23 in the pathogenesis of different diseases.

\begin{tabular}{llc}
\hline Disease & IL-23 effect & References \\
\hline Inflammatory bowel diseases & Pathogenic & $(24,25)$ \\
Rheumatoid arthritis & Pathogenic & $(25,27)$ \\
Psoriasis & Pathogenic & $(23-26)$ \\
Atherosclerosis & Pathogenic & $(28,29)$ \\
MS & Pathogenic & $(13-15,30-32)$ \\
Stroke/postischemic inflammation & Pathogenic & $(33,34)$ \\
Infections & Protective & $(35-37)$ \\
\hline
\end{tabular}

or extracellularly degrade $A \beta$ by enzyme secretion (40). However, they also lead to increased $A \beta$ levels and contribute to tissue reaction and destruction in $\mathrm{AD}$ especially during disease progression (47). In addition, activation of microglia and complement-dependent pathways mediates synapse loss in $\mathrm{AD}$ (48). The state of activation appears to determine whether microglia have a protective or detrimental role in $\mathrm{AD}$ (49). Microglial mediated neuroinflammation is increased in $\mathrm{AD}$ while microglial-mediated $\mathrm{A} \beta$ clearance mechanisms are diminished (41).

Microglia and astrocytes are the major source of proinflammatory cytokines as essential regulators of the immune response in AD (50). IL-1, IL-6, IL-12, IL-23, GMCSF, TNF-, C-X-C motif chemokine ligand 10 (CXCL10) are detectable or upregulated in animal models of $\mathrm{AD}$, in the brain or CSF from $\mathrm{AD}$ patients $(47,51)$. APP/presenilin 1 (APP/PS1) mice, a well-established mouse model to study amyloid pathology in $\mathrm{AD}$, show reduced plaque burden and $\mathrm{A} \beta$ levels if genetically deficient for CXCR3, the receptor for CXCL10 (52). The proinflammatory cytokine milieu in the $\mathrm{AD}$ brain contributes directly or indirectly to neuronal damage. $A \beta$ stimulation results in secretion of proinflammatory cytokines, which trigger neuronal hyperexcitability and synaptic dysfunction (40). Moreover, cytokines stimulate the secretion of inducible nitric oxide synthase in microglia and astrocytes, which is toxic to neurons at high concentrations (40).

\section{IL-23 AND AD}

As the relevance of IL-23 in neuroinflammation, particularly in MS, has become evident, the question of how IL-23 affects inflammatory processes in $\mathrm{AD}$ has arisen. Therefore, several descriptive and experimental studies addressed the impact of IL-12/23 p 40 and IL-23 signaling on AD in recent years.

Single nucleotide polymorphisms in the IL-12/23 subunit p40 (rs3212227) (53) and IL-23 receptor polymorphisms are associated with $\mathrm{AD}$ in a northern Han Chinese population (54).

AD patients show higher peripheral levels of IL-23 (55) and the concentration of the subunit $\mathrm{p} 40$ was identified as a serum marker for the prediction of the $A \beta$ load in an $A D$ cohort (56). A plasma multianalyte profiling study of patients with mild cognitive impairment and $\mathrm{AD}$ demonstrated an association of plasma p40 levels with abnormal cognitive performance (57). 


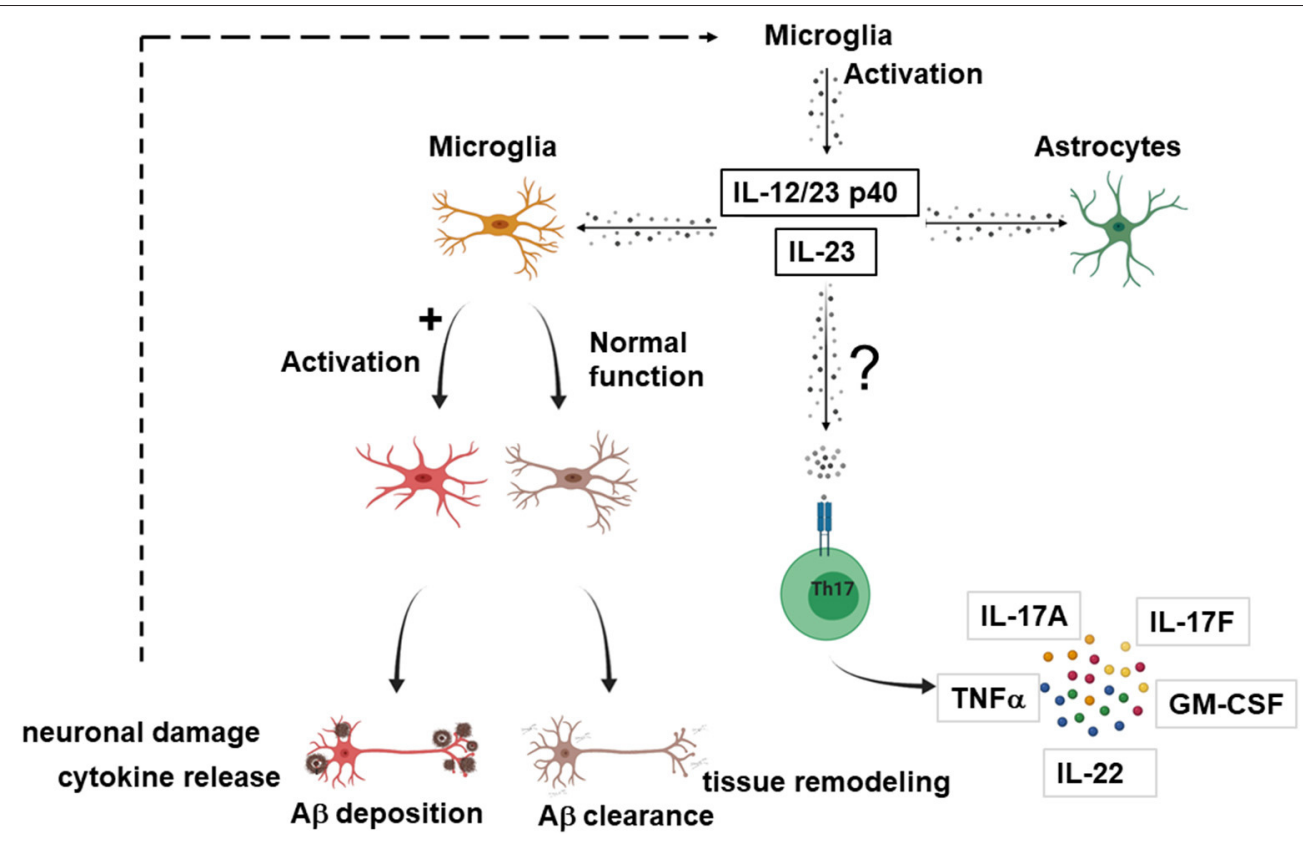

FIGURE 2 | Possible effector cells in IL-23 mediated neuroinflammation in AD. Suggested model how IL-23 and IL-12/23 p40 drives neuroinflammation in AD. Upon activation, microglia secrete IL-23 or/and IL-12/23 p40. IL-23 and IL-12/23 p40 lead to a shift of microglia from A $\beta$ clearance and tissue remodeling toward an activated state with production of proinflammatory cytokines, inhibition of the clearance of $\mathrm{A} \gamma \delta$ neuronal damage, which in turn could further enhance the IL-23 secretion. IL-23 and IL-12/23 p40 could also lead to activation of astrocytes. Nevertheless, it cannot be excluded that the effector cells for IL-23 signaling are partly $T$ cells, as described for other neuroinflammatory diseases. The figure was generated with BioRender.com.

In contrast, a smaller study demonstrated reduced $\mathrm{p} 40$ concentration in CSF in patients with cognitive impairment including $\mathrm{AD}$ in early phases of the disease with a median Mini-Mental State Examination (MMSE) score of 23 (58). However, this study additionally found CSF IL-12/23 p40 concentrations correlated positively with CSF concentrations of A $\beta 1-42$ and phosphorylated tau protein but not MMSE score in the total study population including patients with mild cognitive impairment, $\mathrm{AD}$, and other dementia forms. But in $\mathrm{AD}$ patients CSF IL-12/23 p40 only correlated positively with CSF P-Tau (58). The most extensive study concerning the role of IL-23 in $\mathrm{AD}$ was performed by vom Berg et al. (59). They found increased expression of p40 in microglia in APP/PS1 mice and increased $\mathrm{p} 40$ in cerebrospinal fluid of $\mathrm{AD}$ patients. The cognitive performance measured with the MMSE score correlated in this study negatively with CSF IL-12/23 p40 levels. However, it should be noted that the number of AD patients studied was small $(n=7)$. Furthermore, p40 appears to contribute to the extent of cerebral plaque formation and activation of microglia in the mouse model. Cytokine-knockout (p19, p35, and p40) APP/PS1 mice showed reduced microglial activation and disease severity along with diminished accumulation of $A \beta$ in young and older mice (59). Thereby, loss of the common IL-12/23 p40 subunit did show the greatest impact on $A \beta$ plaque burden, whereas deficiency of the unique subunits IL-23 p19 or IL12 p35 results in a similar but weaker reduction. Moreover, experiments with bone marrow-chimeric mice indicated that microglial cell-derived IL-12/23 p40, but not peripheral myeloid cell-derived IL-12/23 p40 is involved in the extent of in A $\beta$ plaque load. This finding further illustrates the central role of microglia in mediating p40-related effects on $\mathrm{A} \beta$ burden (59). The p40 production by microglia was associated with the de novo expression of the activation marker CD11c indicating modulation of microglia activity when producing p40 (59). In addition, after injection of anti-p40 antibodies before or after the onset of amyloid accumulation, the mice showed reduced $\mathrm{A} \beta$ formation and improved cognitive performance (59). Thus, both female and male mice were used for this study and a gender bias cannot be ruled out. Another study examined the genderspecific effect in mice lacking IL12p40. Eede et al. found that IL12p40 deficiency reduces A $\beta$ plaque burden in male APP23 mice, while female mice had a significant reduction in soluble $\mathrm{A} \beta 1-40$ without changes in $\mathrm{A} \beta$ plaque burden (60). Furthermore, plasma and brain cytokine levels are altered differently in female vs. male APP23 mice lacking IL12p40.

\section{Which Cells Mediate the Effects of IL-23 in AD?}

While the number of leukocyte subpopulations known to respond to IL-23 is growing (14), the effector cells upon IL23 signaling in the context of $\mathrm{AD}$ remain elusive. Although the actions of IL-23 in other neuroinflammatory processes like MS are mediated via Th17 cells $(19,20)$, in AD, IL-23 and IL-12/23 p40 might act through novel mechanisms independent from $\mathrm{T}$ cells. Figure 2 provides a proposed mechanism how IL-23 drives neuroinflammation in AD. 
Vom Berg et al. provided a hypothesis involving cells of the innate immunity as effectors in the p40 driven signaling pathway (59). One possible scenario covers the sustained $A \beta-$ driven release of $\mathrm{p} 40$ by microglia that binds to the IL12R $\beta 1$ receptor on adjacent astrocytes in a paracrine manner. As a second scenario, autocrine activation of microglia by binding of $\mathrm{p} 40$ to the IL12R $\beta 1$ receptor on microglia themselves is suggested, which promotes AD pathology.

However, it should be noted that the p40 subunit alone is in generally not considered a bioactive form. It appears that both subunits, p40 and p19 for IL-23, p40 and p35 for IL-12, must be co-expressed in the same cell to generate the bioactive form (IL12 or IL-23). But several studies in fact show that $\mathrm{p} 40$ alone can act as a messenger substance (61). The p40 homodimer is capable of inducing the expression of immune factors in microglia via the IL-12R $\beta 1$ (62).

Further data are needed to elucidate if neuroinflammation in $\mathrm{AD}$ is driven by IL-12/23 p40, IL-23 or even partly by IL-12. Since p40 is a subunit of both IL-23 and IL-12, this is difficult to determine from the data. The results of the APP/PS1 mouse model with deletion of the unique subunits IL-23 p19 or IL-12 p35, which results in a weaker but similar reduction of the plaque load, speak against the fact that the effect is mediated by $\mathrm{p} 40$ alone (59).

A study analyzing $A \beta$ clearance in IL-23-treated microglia further enlightened, which effector cells might respond to $\mathrm{p} 40$ or IL-23. In a human macrophage cell line A $\beta 42$ incubation increased the expression of IL-17, IL-18, IL-23, whereas the same cytokines impaired $\mathrm{A} \beta$ clearance by macrophages or microglia (63). The inhibitory effects of IL-18 were blocked by IL-23 or IL-17 neutralizing antibodies while the inhibitory effects of IL23 were blocked by IL-17 neutralizing antibodies pointing to an interaction of IL-17, IL-18, and IL-23 and microglia for the $\mathrm{A} \beta$ clearance.

In another mouse model, the senescence-accelerated mouse prone-8 model (SAMP8), Tan et al. screened the cerebral expression of IL-12/23 in 3-, 7-, and 11-month-old mice and demonstrated that these cytokine levels in the brain were upregulated during aging (64). By in vivo infusion of non-viral small interfering RNA (siRNA) to knock down the common IL-12/23 subunit p40 in the brain, they demonstrated that these p40-deficient mice had significantly diminished cerebral A 342 levels, reduced synaptic and neuronal loss, and reversed cognitive impairments. In addition, treatment of the SAMP8 mice with a neutralizing $\mathrm{p} 40$-specific antibody also ameliorated $\mathrm{AD}$-associated pathology and cognitive deficits.

Several studies have demonstrated that microglia can express both neurotoxic and neurotrophic factors (65). Tan et al. hypothesized that the beneficial changes by treatment of SAMP8 mice with a neutralizing $\mathrm{p} 40$-specific antibody might be derived from a shift of microglia from an activated state with release of proinflammatory cytokines and inhibition of the clearance of $A \beta$ toward an increased $A \beta$ clearance and enhanced tissue remodeling.

Nevertheless, it cannot be excluded that the effector cells for p40 or IL-23 signaling are partly T cells, as described for other neuroinflammatory diseases. In a mouse models of $\mathrm{AD}, \mathrm{A} \beta$ vaccination results in a reduction in amyloid burden concomitant with decreased expression of the IL-12R $\beta 1$ receptor by $\mathrm{T}$ cells, the receptor subunit binding to p40 (66). Th17 cell-mediated neuroinflammation is involved in neurodegeneration of a rat AD model (67). Furthermore, activation of Th17 cells in AD patients has been demonstrated by Saresella et al. (68) and Th17 cells, which infiltrated into AD brain parenchyma, participate in neuroinflammation and neurodegeneration of $\mathrm{AD}$ by release of proinflammatory cytokines and by direct action on neurons via the Fas/FasL apoptotic pathway (67). The role of IL-23 and IL$17 \mathrm{a}$, as the signature cytokine of Th17 cells, was also reviewed by Mohammadi Shahrokhi et al. (69), which identified IL-17a as a main inducer of neuroinflammation in $\mathrm{AD}$. In contrast, Saksida et al. identified IL-17 as a rather protective factor. The central finding of the study was a lower production of IL-17 in gut-associated lymphoid tissue cells of aged $5 x F A D$ mice probably due to impaired post-transcriptional stabilization of the IL-17 mRNA mediated by miR-155 (70). The decreased IL17 level could impair the homeostasis of the immune system in the gut-associated lymphoid tissue, but could also contribute to inappropriate $\mathrm{A} \beta$ clearance in gut-associated lymphoid tissue and CNS. Another review speculates about the beneficial use of anti-IL-17A and anti-IL-23 antibody in AD by interfering with neutrophil infiltration and thereby suggets another possible effector cell in IL-23-mediated neuroinflammation in AD (71).

A shift from the Th17 cell/regulatory $\mathrm{T}$ cell balance favoring the proinflammatory Th17 side is suspected to contribute to exacerbation of autoimmune disorders (72). Since regulatory $\mathrm{T}$ cells delay disease progression in $\mathrm{AD}$ pathology (73), the role of regulatory $\mathrm{T}$ cells in IL-23 and $\mathrm{AD}$ should also be enlightened in further studies.

However, it is important to take into account that most data on the functional role of IL-23 in AD have been generated from mouse models, and in particular from the APP/PS1 model, which develops $A \beta$ plaques by 6-8 months, but no tau pathology and does not cover all aspects of AD pathology (74). The effect of IL-23 especially on tau pathology is certainly worthwhile to investigate further.

Nevertheless, the current knowledge of the role of IL-23 and especially the IL-12/23 common subunit p40 are promising. The signaling pathways and effector cells involved in IL-23 and IL-12/23 p40 mediated immune response in AD should be enlightened in further studies, particularly in the clinical context.

\section{IL-23 an Attractive Therapeutic Target in AD?}

Novel therapeutic options such as a variety of antibody therapies have led to significant progress in the treatment of many neurological diseases in recent years. However, the treatment of $\mathrm{AD}$ remains inadequate despite the immense progress in therapeutic options, so that the development of new therapeutic approaches remains a central aspect in $\mathrm{AD}$ research. Modulating the function of IL-23 appears to be an interesting target for $\mathrm{AD}$ although the precise signaling pathways and corresponding effector cells are not completely characterized. The beneficial results of the anti-IL-23 in preclinical studies 
could be transferable to the patient. While antibody therapies that interfere with the IL-23 are firmly established in the therapeutic concept for diseases such as psoriasis, spondylitis ankylosans, or inflammatory intestine illness (75-77), they are yet not established for the treatment of inflammatory CNS diseases. Administration of the p40 antibody ustekinumab was not successful in clinical trials in MS patients (78). Similarly, the anti-p40 antibody briakinumab showed only a slight benefit in terms of imaging progress and clinical relapse rate (79). Nevertheless, clinical trials blocking IL-23 and investigating whether it results in reduced neuroinflammation, reduced plaque burden, and improved cognitive impairment appear worthwhile. Considering the large number of patients already receiving an approved anti-IL23 therapy, studies of whether anti-IL23 therapy can prevent the development of $\mathrm{AD}$ would also be interesting.

These studies should be in particular feasible, as the yet approved anti-IL23 antibody therapies for autoimmune diseases showed a favorable risk profile in terms of safety of use, especially with regard to more severe infections or malignancies $(75,78-80)$.

\section{DISCUSSION}

Taken together, the currently available studies underline the impact of the proinflammatory cytokines of IL-23 and its subunit p40 in the pathogenesis of $\mathrm{AD}$. In addition to clinical data

\section{REFERENCES}

1. Robinson M, Lee BY, Hane FT. Recent progress in Alzheimer's disease research, Part 2: genetics and epidemiology. J Alzheimers Dis. (2017) 57:31730. doi: 10.3233/JAD-161149

2. Holtmann H, Resch K. Cytokines. Naturwissenschaften. (1995) 82:17887. doi: 10.1007/BF01143192

3. Oppmann B, Lesley R, Blom B, Timans JC, Xu Y, Hunte B, et al. Novel p19 protein engages IL-12p40 to form a cytokine, IL-23, with biological activities similar as well as distinct from IL-12. Immunity. (2000) 13:71525. doi: 10.1016/S1074-7613(00)00070-4

4. Becher B, Durell BG, Noelle RJ. IL-23 produced by CNS-resident cells controls $\mathrm{T}$ cell encephalitogenicity during the effector phase of experimental autoimmune encephalomyelitis. J Clin Invest. (2003) 112:118691. doi: 10.1172/JCI200319079

5. Cua DJ, Sherlock J, Chen Y, Murphy CA, Joyce B, Seymour B, et al. Interleukin-23 rather than interleukin-12 is the critical cytokine for autoimmune inflammation of the brain. Nature. (2003) 421:7448. doi: 10.1038/nature01355

6. Pirhonen J, Matikainen S, Julkunen I. Regulation of virus-induced IL-12 and IL-23 expression in human macrophages. J Immunol. (2002) 169:56738. doi: 10.4049/jimmunol.169.10.5673

7. Sun L, He C, Nair L, Yeung J, Egwuagu CE. Interleukin 12 (IL-12) family cytokines: role in immune pathogenesis and treatment of CNS autoimmune disease. Cytokine. (2015) 75:249-55. doi: 10.1016/j.cyto.2015.01.030

8. Constantinescu CS, Tani M, Ransohoff RM, Wysocka M, Hilliard B, Fujioka T, et al. Astrocytes as antigen-presenting cells: expression of IL-12/IL-23. J Neurochem. (2005) 95:331-40. doi: 10.1111/j.1471-4159.2005.03368.x

9. Tribouillard-Tanvier D, Carroll JA, Moore RA, Striebel JF, Chesebro B. Role of cyclophilin A from brains of prion-infected mice in stimulation of cytokine release by microglia and astroglia in vitro. J Biol Chem. (2012) 287:462839. doi: 10.1074/jbc.M111.269480 showing the association of single nucleotide polymorphisms, IL-23 levels and $\mathrm{AD}$, preclinical data demonstrate that IL-23 plays a crucial role in neuroinflammation, plaque formation in $\mathrm{AD}$ models and identify anti-IL-23 therapy as a promising new therapeutic approach. The data suggest that the aspects of IL23 mediated neuroinflammation in $\mathrm{AD}$ remain an interesting research field and further data will enlighten the significance and signaling pathways of IL-23 in AD.

\section{AUTHOR CONTRIBUTIONS}

All authors prepared, corrected, and modified the manuscript.

\section{FUNDING}

MM was a post-doctoral fellow from the Deutsche Forschungsgemeinschaft (DFG, Mu17-07/3-1) and was also supported by the fund Innovative Medical Research of the University of Muenster Medical School, Germany. JZ was funded by the fund Bonfor from the University of Bonn Medical School, Germany and the DFG (KFO177, University of Bonn). LN was funded by the DFG (KFO177, University of Bonn) and the Oppenheim Foerderpreis Novartis $\mathrm{GmbH}$ for a previous project. Novartis GmbH was not involved in the collection, analysis, interpretation of data, the writing of this article or the decision to submit it for publication.
10. Esen N, Kielian T. Central role for MyD88 in the responses of microglia to pathogen-associated molecular patterns. J Immunol. (2006) 176:680211. doi: 10.4049/jimmunol.176.11.6802

11. Derkow K, Krüger C, Dembny P, Lehnardt S. Microglia induce neurotoxic IL$17+\gamma \delta$ T cells dependent on TLR2, TLR4, and TLR9 activation. PLoS ONE. (2015) 10:e0135898. doi: 10.1371/journal.pone.0135898

12. Lv M, Liu Y, Zhang J, Sun L, Liu Z, Zhang S, et al. Roles of inflammation response in microglia cell through Toll-like receptors 2/interleukin23/interleukin-17 pathway in cerebral ischemia/reperfusion injury. Neuroscience. (2011) 176:162-72. doi: 10.1016/j.neuroscience.2010.11.066

13. Endong L, Shijie J, Sonobe Y, Di M, Hua L, Kawanokuchi J, et al. The gap-junction inhibitor carbenoxolone suppresses the differentiation of Th17 cells through inhibition of IL-23 expression in antigen presenting cells. $J$ Neuroimmunol. (2011) 240-1:58-64. doi: 10.1016/j.jneuroim.2011.09.012

14. Pastor-Fernández G, Mariblanca IR, Navarro MN. Decoding IL-23 signaling cascade for new therapeutic opportunities. Cells. (2020) 9:2044. doi: 10.3390/cells9092044

15. Bettelli E, Carrier Y, Gao W, Korn T, Strom TB, Oukka M, et al. Reciprocal developmental pathways for the generation of pathogenic effector TH17 and regulatory T cells. Nature. (2006) 441:235-8. doi: 10.1038/nature04753

16. Mangan PR, Harrington LE, O'Quinn DB, Helms WS, Bullard DC, Elson CO, et al. Transforming growth factor-beta induces development of the $\mathrm{T}(\mathrm{H}) 17$ lineage. Nature. (2006) 441:231-4. doi: 10.1038/nature04754

17. Veldhoen M, Hocking RJ, Atkins CJ, Locksley RM, Stockinger B. TGFbeta in the context of an inflammatory cytokine milieu supports de novo differentiation of IL-17-producing T cells. Immunity. (2006) 24:17989. doi: 10.1016/j.immuni.2006.01.001

18. Liu W, Chang $\mathrm{C}, \mathrm{Hu} \mathrm{H}$, Yang H. Interleukin-23: a new atherosclerosis target. J Interferon Cytokine Res. (2018) 38:440-4. doi: 10.1089/jir.2018.0006

19. Langrish CL, Chen Y, Blumenschein WM, Mattson J, Basham B, Sedgwick JD, et al. IL-23 drives a pathogenic T cell population that induces autoimmune inflammation. J Exp Med. (2005) 201:233-40. doi: 10.1084/jem.20041257 
20. Kebir H, Ifergan I, Alvarez JI, Bernard M, Poirier J, Arbour N, et al. Preferential recruitment of interferon-gamma-expressing TH17 cells in multiple sclerosis. Ann Neurol. (2009) 66:390-402. doi: 10.1002/ana.21748

21. Awasthi A, Riol-Blanco L, Jäger A, Korn $\mathrm{T}$, Pot $\mathrm{C}$, Galileos $\mathrm{G}$, et al. Cutting edge: IL-23 receptor gfp reporter mice reveal distinct populations of IL-17-producing cells. J Immunol. (2009) 182:5904-8. doi: 10.4049/jimmunol.0900732

22. Sonobe Y, Liang J, Jin S, Zhang G, Takeuchi H, Mizuno T, et al. Microglia express a functional receptor for interleukin-23. Biochem Biophys Res Commun. (2008) 370:129-33. doi: 10.1016/j.bbrc.2008.03.059

23. Alunno A, Carubbi F, Cafaro G, Pucci G, Battista F, Bartoloni $\mathrm{E}$, et al. Targeting the IL-23/IL-17 axis for the treatment of psoriasis and psoriatic arthritis. Expert Opin Biol Ther. (2015) 15:1727-37. doi: 10.1517/14712598.2015.1084284

24. Cho JH, Feldman M. Heterogeneity of autoimmune diseases: pathophysiologic insights from genetics and implications for new therapies. Nat Med. (2015) 21:730-8. doi: 10.1038/nm.3897

25. Fragoulis GE, Siebert S, McInnes IB. Therapeutic targeting of IL-17 and IL23 cytokines in immune-mediated diseases. Annu Rev Med. (2016) 67:33753. doi: 10.1146/annurev-med-051914-021944

26. Furue M, Kadono T. Psoriasis: behind the scenes. J Dermatol. (2016) 43:48. doi: 10.1111/1346-8138.13186

27. Zaky DS, El-Nahrery EM. Role of interleukin-23 as a biomarker in rheumatoid arthritis patients and its correlation with disease activity. Int Immunopharmacol. (2016) 31:105-8. doi: 10.1016/j.intimp.2015.12.011

28. Abbas A, Gregersen I, Holm S, Daissormont I, Bjerkeli V, Krohg-Sørensen $\mathrm{K}$, et al. Interleukin 23 levels are increased in carotid atherosclerosis: possible role for the interleukin 23/interleukin 17 axis. Stroke. (2015) 46:7939. doi: 10.1161/STROKEAHA.114.006516

29. Döring Y. Not growth but death: GM-CSF/IL-23 axis drives atherosclerotic plaque vulnerability by enhancing macrophage and DC apoptosis. Circ Res. (2015) 116:222-4. doi: 10.1161/CIRCRESAHA.114.305674

30. Shajarian M, Alsahebfosoul F, Etemadifar M, Sedaghat N, Shahbazi M, Firouzabadi FP, et al. IL-23 plasma level measurement in relapsing remitting multiple sclerosis (RRMS) patients compared to healthy subjects. Immunol Invest. (2015) 44:36-44. doi: 10.3109/08820139.2014.930477

31. Wen SR, Liu GJ, Feng RN, Gong FC, Zhong H, Duan SR, et al. Increased levels of IL-23 and osteopontin in serum and cerebrospinal fluid of multiple sclerosis patients. J Neuroimmunol. (2012) 244:946. doi: 10.1016/j.jneuroim.2011.12.004

32. Li Y, Chu N, Hu A, Gran B, Rostami A, Zhang GX. Increased IL-23p19 expression in multiple sclerosis lesions and its induction in microglia. Brain. (2007) 130:490-501. doi: 10.1093/brain/awl273

33. Shichita T, Sugiyama Y, Ooboshi H, Sugimori H, Nakagawa R, Takada I, et al. Pivotal role of cerebral interleukin-17-producing gammadeltaT cells in the delayed phase of ischemic brain injury. Nat Med. (2009) 15:94650. doi: 10.1038/nm.1999

34. Zheng $\mathrm{Y}$, Zhong $\mathrm{D}$, Chen $\mathrm{H}$, Ma S, Sun $\mathrm{Y}$, Wang $\mathrm{M}$, et al. Pivotal role of cerebral interleukin-23 during immunologic injury in delayed cerebral ischemia in mice. Neuroscience. (2015) 290:321-31. doi: 10.1016/j.neuroscience.2015.01.041

35. Town T, Bai F, Wang T, Kaplan AT, Qian F, Montgomery RR, et al. Tolllike receptor 7 mitigates lethal West Nile encephalitis via interleukin 23dependent immune cell infiltration and homing. Immunity. (2009) 30:24253. doi: 10.1016/j.immuni.2008.11.012

36. Kleinschek MA, Muller U, Brodie SJ, Stenzel W, Kohler G, Blumenschein WM, et al. IL-23 enhances the inflammatory cell response in Cryptococcus neoformans infection and induces a cytokine pattern distinct from IL-12. J Immunol. (2006) 176:1098-106. doi: 10.4049/jimmunol.176.2.1098

37. Meeks KD, Sieve AN, Kolls JK, Ghilardi N, Berg RE. IL-23 is required for protection against systemic infection with Listeria monocytogenes. J Immunol. (2009) 183:8026-34. doi: 10.4049/jimmunol.0901588

38. Hiltensperger M, Korn T. The interleukin (IL)-23/T helper (Th)17 axis in experimental autoimmune encephalomyelitis and multiple sclerosis. Cold Spring Harb Perspect Med. (2018) 8:a029637. doi: 10.1101/cshperspect.a029637

39. Nitsch L, Zimmermann J, Krauthausen M, Hofer MJ, Saggu R, Petzold GC, et al. CNS-specific synthesis of interleukin 23 induces a progressive cerebellar ataxia and the accumulation of both $\mathrm{T}$ and $\mathrm{B}$ cells in the brain: characterization of a novel transgenic mouse model. Mol Neurobiol. (2019) 56:7977-93. doi: 10.1007/s12035-019-1640-0

40. Webers A, Heneka MT, Gleeson PA. The role of innate immune responses and neuroinflammation in amyloid accumulation and progression of Alzheimer's disease. Immunol Cell Biol. (2020) 98:28-41. doi: 10.1111/imcb.12301

41. Sarlus H, Heneka MT. Microglia in Alzheimer's disease. J Clin Invest. (2017) 127:3240-9. doi: 10.1172/JCI90606

42. Brosseron F, Krauthausen M, Kummer M, Heneka MT. Body fluid cytokine levels in mild cognitive impairment and Alzheimer's disease: a comparative overview. Mol Neurobiol. (2014) 50:534-44. doi: 10.1007/s12035-014-8657-1

43. Tarkowski E, Andreasen N, Tarkowski A, Blennow K. Intrathecal inflammation precedes development of Alzheimer's disease. J Neurol Neurosurg Psychiatry. (2003) 74:1200-5. doi: 10.1136/jnnp.74.9.1200

44. Hamelin L, Lagarde J, Dorothée G, Leroy C, Labit M, Comley RA, et al. Early and protective microglial activation in Alzheimer's disease: a prospective study using 18F-DPA-714 PET imaging. Brain. (2016) 139:125264. doi: 10.1093/brain/aww017

45. Navarro V, Sanchez-Mejias E, Jimenez S, Muñoz-Castro C, SanchezVaro R, Davila JC, et al. Microglia in Alzheimer's disease: activated, dysfunctional or degenerative. Front Aging Neurosci. (2018) 10:140. doi: 10.3389/fnagi.2018.00140

46. Hemonnot AL, Hua J, Ulmann L, Hirbec H. Microglia in Alzheimer disease: well-known targets and new opportunities. Front Aging Neurosci. (2019) 11:233. doi: 10.3389/fnagi.2019.00233

47. Heppner FL, Ransohoff RM, Becher B. Immune attack: the role of inflammation in Alzheimer disease. Nat Rev Neurosci. (2015) 16:35872. doi: $10.1038 / \mathrm{nrn} 3880$

48. Hong S, Beja-Glasser VF, Nfonoyim BM, Frouin A, Li S, Ramakrishnan S, et al. Complement and microglia mediate early synapse loss in Alzheimer mouse models. Science. (2016) 352:712-6. doi: 10.1126/science.aad8373

49. Krause DL, Müller N. Neuroinflammation, microglia and implications for anti-inflammatory treatment in Alzheimer's disease. Int J Alzheimers Dis. (2010) 2010:732806. doi: 10.4061/2010/732806

50. Streit WJ, Mrak RE, Griffin WS. Microglia and neuroinflammation: a pathological perspective. J Neuroinflammation. (2004) 1:14. doi: 10.1186/1742-2094-1-14

51. Duan RS, Yang X, Chen ZG, Lu MO, Morris C, Winblad B, et al. Decreased fractalkine and increased IP-10 expression in aged brain of APP(swe) transgenic mice. Neurochem Res. (2008) 33:1085-9. doi: 10.1007/s11064-007-9554-Z

52. Krauthausen M, Kummer MP, Zimmermann J, Reyes-Irisarri E, Terwel $\mathrm{D}$, Bulic B, et al. CXCR3 promotes plaque formation and behavioral deficits in an Alzheimer's disease model. J Clin Invest. (2015) 125:36578. doi: 10.1172/JCI66771

53. Zhu XC, Tan L, Jiang T, Tan MS, Zhang W, Yu JT. Association of IL-12A and IL-12B polymorphisms with Alzheimer's disease susceptibility in a Han Chinese population. J Neuroimmunol. (2014) 274:180-4. doi: 10.1016/j.jneuroim.2014.06.026

54. Liu Y, Yu JT, Zhang W, Zong Y, Lu RC, Zhou J, et al. Interleukin-23 receptor polymorphisms are associated with Alzheimer's disease in Han Chinese. J Neuroimmunol. (2014) 271:43-8. doi: 10.1016/j.jneuroim.2014. 03.013

55. Chen JM, Jiang GX, Li QW, Zhou ZM, Cheng Q. Increased serum levels of interleukin-18,-23 and-17 in Chinese patients with Alzheimer's disease. Dement Geriatr Cogn Disord. (2014) 38:321-9. doi: 10.1159/000360606

56. Pedrini S, Gupta VB, Hone E, Doecke J, O’Bryant S, James I, et al. A blood-based biomarker panel indicates IL-10 and IL-12/23p40 are jointly associated as predictors of $\beta$-amyloid load in an AD cohort. Sci Rep. (2017) 7:14057. doi: 10.1038/s41598-017-14020-9

57. Hu WT, Holtzman DM, Fagan AM, Shaw LM, Perrin R, Arnold SE, et al. Plasma multianalyte profiling in mild cognitive impairment and Alzheimer disease. Neurology. (2012) 79:897-905. doi: 10.1212/WNL.0b013e3182 $66 \mathrm{fa} 0$

58. Johansson P, Almqvist EG, Wallin A, Johansson JO, Andreasson U, Blennow $\mathrm{K}$, et al. Reduced cerebrospinal fluid concentration of interleukin-12/23 subunit p40 in patients with cognitive impairment. PLoS ONE. (2017) 12:e0176760. doi: 10.1371/journal.pone.0176760 
59. Vom Berg J, Prokop S, Miller KR, Obst J, Kälin RE, Lopategui-Cabezas I, et al. Inhibition of IL-12/IL-23 signaling reduces Alzheimer's disease-like pathology and cognitive decline. Nat Med. (2012) 18:1812-9. doi: 10.1038/nm.2965

60. Eede P, Obst J, Benke E, Yvon-Durocher G, Richard BC, Gimber $\mathrm{N}$, et al. Interleukin-12/23 deficiency differentially affects pathology in male and female Alzheimer's disease-like mice. EMBO Rep. (2020) 21:e48530. doi: 10.15252/embr.201948530

61. Gately MK, Carvajal DM, Connaughton SE, Gillessen S, Warrier RR, Kolinsky KD, et al. Interleukin-12 antagonist activity of mouse interleukin12 p40 homodimer in vitro and in vivo. Ann N Y Acad Sci. (1996) 795:112. doi: 10.1111/j.1749-6632.1996.tb52650.x

62. Jana M, Dasgupta S, Pal U, Pahan K. IL-12 p40 homodimer, the so-called biologically inactive molecule, induces nitric oxide synthase in microglia via IL-12R beta 1. Glia. (2009) 57:1553-65. doi: 10.1002/glia.20869

63. Chen JM, Li QW, Jiang GX, Liu JS, Cheng Q. IL-18 induced IL-23/IL-17 expression impairs A $\beta$ clearance in cultured THP-1 and BV2 cells. Cytokine. (2019) 119:113-8. doi: 10.1016/j.cyto.2019.03.003

64. Tan MS, Yu JT, Jiang T, Zhu XC, Guan HS, Tan L. IL12/23 p40 inhibition ameliorates Alzheimer's disease-associated neuropathology and spatial memory in SAMP8 mice. J Alzheimers Dis. (2014) 38:63346. doi: $10.3233 /$ JAD-131148

65. Ransohoff RM. A polarizing question: do M1 and M2 microglia exist? Nat Neurosci. (2016) 19:987-91. doi: 10.1038/nn.4338

66. Town T, Vendrame M, Patel A, Poetter D, DelleDonne A, Mori T, et al. Reduced Th1 and enhanced Th2 immunity after immunization with Alzheimer's beta-amyloid(1-42). J Neuroimmunol. (2002) 132:4959. doi: 10.1016/S0165-5728(02)00307-7

67. Zhang J, Ke KF, Liu Z, Qiu YH, Peng YP. Th17 cell-mediated neuroinflammation is involved in neurodegeneration of $\mathrm{a} \beta \mathrm{B}$ 42-induced Alzheimer's disease model rats. PLoS ONE. (2013) 8:e75786. doi: 10.1371/journal.pone.0075786

68. Saresella M, Marventano I, Calabrese E, Piancone F, Rainone V, Gatti A, et al. A complex proinflammatory role for peripheral monocytes in Alzheimer's disease. J Alzheimers Dis. (2014) 38:403-13. doi: 10.3233/JAD-131160

69. Mohammadi Shahrokhi V, Ravari A, Mirzaei T, Zare-Bidaki M, Asadikaram G, Arababadi MK. IL-17A and IL-23: plausible risk factors to induce ageassociated inflammation in Alzheimer's disease. Immunol Invest. (2018) 47:812-22. doi: 10.1080/08820139.2018.1504300

70. Saksida T, Koprivica I, Vujičić M, Stošić-Grujičić S, Perović M, Kanazir S, et al. Impaired IL-17 production in gut-residing immune cells of 5xFAD mice with Alzheimer's disease pathology. J Alzheimers Dis. (2018) 61:61930. doi: 10.3233/JAD-170538

71. Katayama H. Anti-interleukin-17A and anti-interleukin-23 antibodies may be effective against Alzheimer's disease: role of neutrophils in the pathogenesis. Brain Behav. (2020) 10:e01504. doi: 10.1002/brb3.1504

72. Fasching P, Stradner M, Graninger W, Dejaco C, Fessler J. Therapeutic potential of targeting the Th17/Treg axis in autoimmune disorders. Molecules. (2017) 22:134. doi: 10.3390/molecules22010134
73. Dansokho C, Ait Ahmed D, Aid S, Toly-Ndour C, Chaigneau $\mathrm{T}$, Calle $\mathrm{V}$, et al. Regulatory $\mathrm{T}$ cells delay disease progression in Alzheimer-like pathology. Brain. (2016) 139:1237-51. doi: 10.1093/brain/ awv408

74. Myers A, McGonigle P. Overview of transgenic mouse models for Alzheimer's disease. Curr Protoc Neurosci. (2019) 89:e81. doi: 10.1002/cpns.81

75. Blauvelt A, Papp KA, Griffiths CE, Randazzo B, Wasfi Y, Shen YK, et al. Efficacy and safety of guselkumab, an anti-interleukin-23 monoclonal antibody, compared with adalimumab for the continuous treatment of patients with moderate to severe psoriasis: results from the phase III, double-blinded, placebo- and active comparator-controlled VOYAGE 1 trial. J Am Acad Dermatol. (2017) 76:405-17. doi: 10.1016/j.jaad.2016. 11.041

76. Kavanaugh A, Menter A, Mendelsohn A, Shen YK, Lee S, Gottlieb AB. Effect of ustekinumab on physical function and health-related quality of life in patients with psoriatic arthritis: a randomized, placebo-controlled, phase II trial. Curr Med Res Opin. (2010) 26:2385-92. doi: 10.1185/03007995.2010.515804

77. Argollo MC, Allocca M, Furfaro F, Peyrin-Biroulet L, Danese S. Interleukin-23 blockers: born to be first-line biologic agents in inflammatory bowel disease? Curr Pharm Des. (2019) 25:25-31. doi: 10.2174/13816128256661903131 40811

78. Segal BM, Constantinescu CS, Raychaudhuri A, Kim L, FidelusGort R, Kasper LH, et al. Repeated subcutaneous injections of IL12/23 p40 neutralising antibody, ustekinumab, in patients with relapsing-remitting multiple sclerosis: a phase II, double-blind, placebocontrolled, randomised, dose-ranging study. Lancet Neurol. (2008) 7:796-804. doi: 10.1016/S1474-4422(08)70173-X

79. Vollmer TL, Wynn DR, Alam MS, Valdes J. A phase 2, 24-week, randomized, placebo-controlled, double-blind study examining the efficacy and safety of an anti-interleukin-12 and-23 monoclonal antibody in patients with relapsingremitting or secondary progressive multiple sclerosis. Mult Scler. (2011) 17:181-91. doi: 10.1177/1352458510384496

80. Macaluso FS, Orlando A, Cottone M. Anti-interleukin-12 and antiinterleukin-23 agents in Crohn's disease. Expert Opin Biol Ther. (2019) 19:8998. doi: 10.1080/14712598.2019.1561850

Conflict of Interest: The authors declare that the research was conducted in the absence of any commercial or financial relationships that could be construed as a potential conflict of interest.

Copyright $\odot 2021$ Nitsch, Schneider, Zimmermann and Müller. This is an openaccess article distributed under the terms of the Creative Commons Attribution License (CC BY). The use, distribution or reproduction in other forums is permitted, provided the original author(s) and the copyright owner(s) are credited and that the original publication in this journal is cited, in accordance with accepted academic practice. No use, distribution or reproduction is permitted which does not comply with these terms. 